\title{
MULTICULTURAL DISCOURSE OF MODERN ADVERTISING
}

Assoc. Prof. Elena A. Nozdrenko PhD ${ }^{1}$

Assoc. Prof. Elena A. Ponomareva PhD $^{2}$

Assoc. Prof. Irina A. Panteleeva PhD $^{3}$

Assoc. Prof. Elena V. Mylnikova PhD ${ }^{4}$

\section{ABSTRACT}

Purpose. Advertising contributes to the emergence of a new reality, characterized by increasing the integrity of the variety of different cultures, traditions, religions and values. Modern social relations and globalization processes actualize the question of identity of any culture. Modern advertising involves the context of another culture, appealing to basic ideals of their culture, taking into account cultural identity of perception. The purpose of the research - to analyze the phenomenon of advertising in the context of a multicultural discourse, as its content and perception is always formed under the conditions of mixing and interpenetration of cultures.

Design/methodology/approach. Basic principles of dialectical logic were applied as a theoretical and methodological foundations of the research (ascent from the abstract to the concrete, the ratio of the empirical and theoretical, unity of the historical and logical).

Findings. Multicultural discourse of modern advertising reveals the concept of dialogue between cultures through understanding of their own cultural type. Signs of national identity are not static and can change. The idea of universalism is dangerous for the modern world, and advertising has all possibilities to actively participate in the complex process of identity formation of any culture. Actual cultural values and images are broadcasted by multicultural determinants for the preservation of national identity (values, symbols, language, mentality, and others). One of the tasks of advertising is mutual understanding of generations and preservation of past experience in the culture.

Originality/value. The theory of multicultural discourse is fundamentally important for global marketing. The specific of advertising as a special object of scientific investigation has been revealed in the article, disclosing the specific content of the abstract philosophical and cultural concepts and principles; A comprehensive analysis of the determinants of multicultural advertising as contradictory and contagious ways of intercultural communication in the process of social interaction in his semioticsymbolic aspect has been carried out. The study will help to understand the specific of Russian advertising concept. The main provisions are aimed at improving the effectiveness of programs of promotion in various markets. interaction.

Keywords: advertising, identity, culture, globalization, discourse, social

Advertising content and its perception are always formed under the conditions of mixing and interpenetration of different cultures. So, the advertising can be considered in the context of a multicultural discourse. The relevance of this study is dictated by the fact that the global world determines the rules of the game on the market, advertising is

\footnotetext{
${ }^{1}$ Siberian Federal University, Russia

${ }^{2}$ Moscow State University of International Relations (MGIMO-University), Russia

${ }^{3}$ Siberian Federal University, Russia

${ }^{4}$ Siberian Federal University, Russia
} 
not the exception here. Researches from different countries show their interest to the problems of multicultural advertising phenomenon, determining the importance of critical discourse analysis to interpret the meaning and understanding of advertising phenomenon.

The difference between modern and postmodern approaches to advertising is studied and propose a methodology of critical discourse analysis to interpret the meaning and understanding the structure of advertising messages [14]. Fears about the commercialization of culture are put forward and develop methods for measuring the cultural nature of advertising, expressing doubt that advertising mirrors the social values [12]. The cultural perspective of the international regulation of advertising is studied and argue that local cultures are in need of protection by regulating advertising [5]. The thesis that the promotional activities of multinational corporations destroying valuable structures of indigenous peoples in the process of creating a "consumer culture» is put forward [6].

The place of advertising in the global culture is discussed, highlighting the complexity of the global / local relationships and asserting that the global advertising is not a global culture or universal values, but is merely a continuation of what happens in the West [7]. The problem of use and abuse of cultural elements in multicultural advertising is studied, believing that their unqualified use reduces the reputational brand equity [2]. The decisive role of advertising in the formation of consumer culture is determined. The concept of Pierre Bourdieu's cultural capital is modernized, arguing that social elites more omnivorous in their tastes, and cultural capital today must increasingly be associated with knowledge of the trendy, not only the fine arts [15]. The different levels of ethnic identity from the perspective of values advocacy advertising are explored [9]. According to the researchers [8] there is a continuous increase in an international advertising research in modern practice. At the same time we agree with authors that the theoretical basis of this perspective should also be improved, and scholarly endeavors needed to identify the diversity of intercultural discourse advertising phenomenon.

While there appears to be an increase in international publishing activity in advertising compared to data extrapolated from past studies, published advertising research still reveals a North American bias/domination. A failure to be globally inclusive may lead to an under-exploration of academic issues and perspectives, as important 'non-US' issues could possibly be ignored [13]. We subscribe to M. Polonsky and L. Carlson, in the hope that the Russian concept of a multicultural discourse of modern advertising will contribute to the investigated issues.

\section{Multicultural discourse}

In this study authors understand advertising as a factor of a controversial process of the creation, saving and changing the basic ideals of the culture, that is using the mechanisms of mass communication in order to simulate the consumer's behaviour. In our study such cultural factors as a values and mentality are examined.

Values. The world of a culture is a world where each culture is represented by a set of values shared by the overwhelming majority of its representatives. In the process of globalisation with cultural peculiarities of each country, the system of human values plays the role of an unifying element. Global consumer culture is recognised as a collection of common signs and symbols (e.g. brands) that are understood by significant numbers of consumers in urban markets around the world [1]. Thus, a product being advertised in the social advertising can be called a life mission, because this advertising deals with such categories as charity, health, art, happiness, religion and love. 
Values transmitted by advertising, are always associated with the manners of its era, and the consumer behaviour dramatically depends on the prevailing values of a particular society. In the modern Russian advertising there is still the domination of motives to improve the quality of life, where the physical frame of a man becomes almost the object of a worship (prevention of aging, anti-wrinkle, care of the figure, etc.). The critics of the modern advertising claim that the advertising negatively affects the system of human values. It is due to the fact that the advertising promotes the way to happiness through the acquisition of material things, and not through the spiritual and moral development. But in any culture with different value systems a modern man is relatively free in his choice. It is he who determines his own border, which seeks to satisfy his own desires, needs and fantasies according to his own ideals. The perception of values is always defined relatively to an ideal, refers to the personality, the structure of self-consciousness and therefore personal needs. Authors recognize that the attention paid to the material things, does not rejects the spiritual and cultural values.

Thus, the social role of the advertising is to improve the basic spiritual values, which are vital to every society. The values, as being an existentially heartfelt, describe the human dimension of the social consciousness. Values are presented in every culture - they are not only distributed but also generated by advertising. Values orient human activity in a given direction.

Mentality. The mentality always motivates the course of human actions, but do not always offer reflecting patterns of human behaviour. The destruction of the mental space of a culture means the destruction of the values in its system. The mentality enables to connect analytical thinking with the cultural codes, integrated in the advertising message. With the mentality people can recognize not only individual cultural clichés, but also a way of thinking, different types of communities (the difference between the European and American, Western and African cultures, totalitarian and bureaucratic mentality, national and children's mental consciousness). The mentality delivers materials to the advertising and creates the basic elements of its concept.

The Russian culture is characterized by the mental unity of the different cultures that are genetically ascending to different ethnic, linguistic and civilizational roots. They refer to the traditions of the intercultural dialogue in the value-semantic space of Russian culture. The advertising reflects a picture of the world, including in its message such categories as imagination on the personality, its relation to a society, freedom, equality, honour, kindness and evil, truth and work, family and sexual relations, historical process and values of time, relationship between the new and the old, death and soul. So, the advertising transforms the mentality through the learning process, which changes the tastes and habits of the individuals. Since the mentality is not reflective and has the property of stereotypes, its displaying in the advertising has a subconscious nature of the response. And a high resistance of the mentality increases the advertising impact on the consumer. The Russian culture is characterized by the mental unity of the different cultures that are genetically ascending to different ethnic, linguistic and civilizational roots. They refer to the traditions of the intercultural dialogue in the value-semantic space of Russian culture. The advertising reflects a picture of the world, including in its message such categories as imagination on the personality, its relation to a society, freedom, equality, honour, kindness and evil, truth and work, family and sexual relations, historical process and values of time, relationship between the new and the old, death and soul. So, the advertising transforms the mentality through the learning process, which changes the tastes and habits of the individuals. The modern society is characterized by a tendency of stereotyping, that is, 
the presence of certain paradigms in relation to certain objects and phenomena. This fact bears evidence of creation of a society that thinks in images and it is very convenient for advertisement. In the modern society stereotypes made the process of comprehension easier, and, therefore, effective [11].

Thus, the discourse of modern Russian advertising is being formed under the conditions of mixing and interpenetration of cultures, while changing and adapting the cultures as well. (1) For the modern Russian advertising it is typical to emerge the new value motives. Radical changes in the centuries-old value orientations are observed. The new values reflected in the advertising promote the birth of a new changed structure of life. The existing in the culture values reflected in the advertising orient the human activity in a particular direction as a vector of its development. (2) The advertising always contains normative behaviour patterns of a particular culture, both on the micro and macro levels. The mental unity and differences in cultural existing in advertising, ascending to the various ethnic, linguistic and civilizational roots of the historical destiny, geopolitical interests and the space areas as well as to the traditions of intercultural dialogue in the value-semantic space of cultures. (3) Values presented in the advertising, play the role of regulations in order to identify the target audience with the religious, ethnic or social groups. On the other hand, the advertising reinforces the stereotypes of the behaviour, acting as a regulatory mechanism that affects a society.

The language of advertising as a universal form to understand the reality in the intercultural communication

The advertising development is associated with the projection of a radical transformation of the categorical model of the world. One of the objectives of the advertising language, as the means of intercultural communication, is to determine mutual understanding between generations and to preserve the past experience in the culture. Therefore, the understanding of advertising as the means of the intercultural communication equals to understanding the language of the previous and surrounding culture in the process of understanding the reality. In the area of a social interaction the language serves as a mean to give intersubjective cultural importance to a subjective experience. It translates socially significant associations, gives them universally significant, shared sense. The language of advertising acts as a universal form of understanding the reality. The global communication problem (the problem of understanding) lies in the transferring the meanings from one language to another. In multilingual advertising, a foreign language is often used for symbolic purposes. The assumption is that the associations carried by the foreign language are transferred to the product that is advertised. The difficulty of understanding of the advertising message is caused by the fact that the perception and behaviour are determined by stereotypes (ideological, national, class, sex), formed in the person's own cultural environment. The understanding is apperceptional, in other words new advertising information is assimilated with the references to already known facts. The new knowledge and new experiences are included in the existing knowledge and on this basis the advertising material is being selected and enriched.

From the semiotic point of view the system of signs is recognized as the basic structural unit of a cultural language. The existence of a sign makes it possible to transmit the advertising message through technical channels of communication and its various processing (mathematical, statistical, logical). It is known that there is no culture without signs, which carry multivariate information and meanings. A person born in a particular culture learns the meanings and values of its symbols. While providing the integration of the society the advertising at the same time affects the socio-cultural differentiation. In other words, the advertising does always correlate individual societies and their semantic-symbolic constructions. 
The correct decoding of the advertising message in a different culture may cause a problem, if it contains an unfamiliar to a target audience code. More obviously this can be seen in the situation when megabrands are introduced on the national markets where the local consumers are offered an advertised product, absolutely not adapted to this consumer market. In this case, the advertising is not activated, and therefore - does not reach the goal. "Alien" culture seems incomprehensible, and that's why the entry into a different culture is associated primarily with the opening of its sign system. The language is formed where the sign deliberately separates from the presentation, and begins to function as a representative of this association and its provider. Typical features of the recording systems can be revealed in advertisement: (1) the sign system in advertising, in its origin, is based on the other sign systems of the language like music, dance, and (2) it is consequent to them, which is expressed, for an example, in a logo which it a part of the corporate identity system. A simulacrum is one of the types of signs in the postmodern period. The theory of "symbolic exchange" by J. Baudrillard identifies items as a carrier of the indexed social values, social and cultural hierarchy, which actually form a certain code which people use to talk in accordance with their class dialect. Today, the content of "simulacrum" is treated as a snag, images, absorbing reality.

In humans, there is always a subjective view of the external environment - a model of the world, consisting of numbers of images. This mental model of the world is mostly based on the information from the environment delivered by the media of communication. Cultural relationships with the self, personality, and attitude are the basis of consumer behavior models and branding and advertising strategies [10]. The advertisement broadcasts the model of the world, which is clear to the target audience, at the every stage of the cultural-historical process, and corresponds to the prevailing their basic ideals. The simulacrum, which is a simulation but not the copy, issues the absence instead of presence, while mixing the distinction between the reality and the imaginary. Dealing with the problem of simulacrum, G. Deleuze emphasized that the simulacrum is a sign that denied the original and the copy either; it is a construction that includes a view of the observer [3]. Then the advertising, of course, translates such structures, which are demanded in a particular culture, demanded here and now with a certain point of view.

The process of cognition in modern Russia is conceived as a design or a simulation of the reality, created by an artificial reality. The cult Russian writer V. Pelevin dedicated his famous novel "The Generation "P" " to "advertising communications at the virtual business era", to the creation "of appearances" (simulacrum), implemented with the help of advanced advertising technologies, where he makes fun of the low level of advertising with its primitive vocabulary and slogans. With the rapid development of new information technologies the two current traditional types of culture - personal contacts (direct communication culture and book culture) are added by the third type of culture - the culture of the screen. This new concept of the modern culture as fragmentary, Alvin Toffler defined as "clip culture", and J. Baudrillard calls it "the Xerox of culture" (the culture of copy"). This type of culture is supported by "aggressive visualization" with the help of media and electronic networks. The television advertising and advertising in the Internet can become as a bright example of the process of cognition.

Thus, the language of advertising serves as the universal form to understand the reality of a culture. It enables people to enter communication connections with each other and to orient in the space of different cultures: 
- The language of advertising reflects the culture of a particular society, as it does not only translate the real world around us, but also the mentality of the people, its national character, traditions, customs, morals, norms and values system. It is a reflection of the world picture.

- The language of advertising facilitates the identification of the foreign cultural products in a borderless cultural and national perception of the world.

- The language of advertising facilitates the socio-economic human adaptation to current conditions and the interpenetration of cultures in the environment.

- The language of advertising can be described as one of the tools of formation of a personality which is perceived through messages, its mentality, traditions and specific cultural image of the world.

Symboling in the intertextual advertising. A text is a synthetic generalized form of the language of a culture. The interpretation of the concept of "text" is not reduced to the act of speech or to a set of statements recorded in the written form. The entire world can be viewed as a text. The advertising text can be defined as a set of symbolic systems, endowed with a certain value. Every phenomenon of a culture is a text, which is composed by people using sign systems. From this point of view, a text - is the basis of culture, and culture itself can be interpreted as a set, a certain system of texts. Therefore, the knowledge of the culture is the knowledge of the text.

A text of advertising as a unit of sign communication of sociocultural communication, cannot have a single interpretation, there are always options of interpretations. It contains a polysemy expressed in the simultaneous deny of centricity and multiplicity of meanings, where everything is important and deserves attention. The advertising text can have a lot of meanings, and may contain different subjective sense. The difference in cultural contexts is considerably important because of the difference in reproducing the text and the multiplicity of its values (hidden meanings). "Meanings are born in a vacuum arising between the lines" (M. Foucault). Thus, the recipient of the advertising message has a freedom of interpretation, when he gets the opportunity to create new meanings, corresponding to his own desires and needs. Regarding to this, the advertising often uses the concept of "non-speaking" and "innuendo" when a consumer or a buyer receives an opportunity to be involved in the interpretation process, where the desire and emotions are formed with a respect to the represented product. An erotic textual body, created by the double analogy (text as a body and the body as text) is directly related to the interpretation of the advertising message. Thus, when decoding of the advertising text there is an influence on the sexual sphere and emotions of a consumer of the advertising information that accelerates the process of deciding to change his own consumer behaviour, expressed in the desire to make a purchase. The desire in this case is interpreted as a modified requiremental field of the culturally associated with the possession of the advertised product.

The modern approach to the theory of advertising communication provides that the mechanism of its affection on consumers is considered not as coercion, but as a seduction by the advertising discourse. And the seduction is inherent to every discourse in all over the world. In the world practice about $30 \%$ of advertising appeals to the sexual sphere. Advertising discourses reinforce gender stereotypes - the male dominance and the female subordination (but it is relevant only in those cultures where women are dominated by the man position). The sexual symbolism in the advertising reveals appropriate emotions and provides changes in the consumer behaviour. Advertising text, entering the new historical and cultural context, replenished with a 
new meaning, different from what it used to have at the time of its creation. Thus, the understanding of the cultural works can never be final and the only true. According to the representatives of post-structuralism - the text is a field, which gives a meaning. Texts live in history, and through the dialog with them the new generations comprehend their contents again and again while searching for the new answers to life's questions.

The image advertising can be correlated with the symbolic production, in the creation of which there is always a kind of sign-symbolic design, which fits this or that product. Each era has its own system of symbols, which acts and is studied as a specific cultural code. Under the cultural code it is usually understood a kind of matrix, underlying self-organization of the society, which is changing in different historical periods. The usage in advertising of such a creative method as "return to the past", due to the appeal to the traditions through symbols, images, etc., where the advertised product is placed in a particular era or style of old. Addressing to the target audience, the advertising is representing the product as a symbol, the possession of which confirms a person belonging to a particular social group. A man is an egoistic nature, but at the same time he always strives to belong to a social group. The studies show that up to $85 \%$ of the advertising contains elements, which appeal to some archetype content. Consequently, the advertising can be considered in the context of its symbolic impact when the information is encoded in its report to the character corresponding to the validity of the subjective individual. In this sense, the true definition of advertising is "trade in images".

Thus, by using the language of symbols associated with the deep archetype sense, the purpose of advertising in the cultural-historical process can be understood, when there is a displacement of space and time in the advertising message. Modern researchers predict that the process of the formation of the symbolic value of the product will be one of the prospective areas of advertising activity in Russia. The symbols of advertising are filled with the actual for the society content, and the social role of advertising in this case is to provide the universal entire understanding of symbols in their new conventional filling, which affects the destiny of a man, and hence the society in which he lives.

Conclusions. The multicultural discourse of modern advertising reveals the concept of dialogue between cultures through an understanding of their own cultural type. This process is accompanied by a study of their own traditions that are meaningful in the context of other cultures. It is important to understand that the features of national identity are not of static nature and are subject to change. Five key areas for research development of Multicultural marketplaces are specified, each with a different conceptual focus: increasing complexity of cultural identities (identity), differentiation of national political contexts (national integration policies), intergroup conviviality practices and conflictual relationships (intergroup relations), interconnectedness of transnational networks (networks), and cultural dynamics requiring multicultural adaptiveness (competences) [4]. The idea of universalism is dangerous for the modern world. Advertising has all resources to actively participate in the complex process of identity formation of any culture. The actual cultural values and images are delivered by multicultural fundamentals (values, symbols, language, mentality and others) for the preservation of national identity.

The social role of advertising is to enhance the formation of the basic and spiritual ideals and values. Symbolic forms of advertising, simultaneously belonging to many cultures, influence the course of human life only in private, historically conditioned form. Specifics of advertising are expressed in the language of symbols associated with the deep sense archetype. Advertising is able to create an artificial world, where the 
reality is marked by certain symbols that create the ground for intercultural communication and interaction. The multicultural concept of advertising provides with a uniform understanding and interpretation of the meaning in its new conventional filling. It is known that the history of culture is reflected in the history of the language development. Then one of the objectives of advertising language, as the means of intercultural communication, is a mutual understanding between generations and preservation the past experience in the culture.

\section{References}

1. Akaka, M.A. and Alden, D.L. (2010), "Global brand positioning and perceptions", International Journal of Advertising, Vol. 29, pp. 37-56.

2. Burgos, W.D. (2008), "Use and Abuse of Cultural Elements in Multicultural Advertising”, Journal of Advertising Research, Vol. 48 No. 2, pp. 177-178.

3. Deleuze, G. (1990), Plato and the Simulacrum. The Logic of Sense, The Athlone Press, London.

4. Demangeot, C., Broderick, A. J. and Craig, C. S. (2015), "Multicultural marketplaces: New territory for international marketing and consumer research", International Marketing Review, Vol. 32 No. 2, pp. 118-140.

5. Frith, K. T. (2003), "Advertising and the homogenization of cultures: Perspectives from ASEAN", Asian Journal of Communication, Vol. 13 No.1, pp. 37-54.

6. Frith, K. T. and Frith, M. (1990), "Western Advertising and Eastern Culture: The Confrontation in Southeast Asia", Current Issues and Research in Advertising, Vol. 12 No. 1-2, pp. 63-73.

7. Gram, M. PhD. (2007), "Whiteness and Western Values in Global Advertisements: An Exploratory Study", Journal of Marketing Communications, Vol. 13 No. 4, pp. 291-309.

8. Khang, H., Sangpil, H., Sumin, S., Jung, A-R. and Kim, Mi-J. (2016), “A retrospective on the state of international advertising research in advertising, communication, and marketing journals: 1963-2014", International Journal of Advertising, Vol. 35 No. 3, pp. 540-568.

9. Lee, Y.-J., Liu, Y.-I and Lee, T. (2013), "Effects of Ethnic Identity on Perceived Advertisers' Motives in Values Advocacy Advertising”, Journal of Promotion Management, Vol. 19 No. 5, pp. 583-604.

10. Mooij, M. and Hofstede, G. (2011), "Cross-Cultural Consumer Behavior: A Review of Research Findings", Journal of International Consumer Marketing, Vol. 23 No. 3-4, pp.181-192.

11. Nozdrenko E. Advertisement as Meaning-Making Element of Stereotypes Formation in the Modern Society. Journal of Siberian Federal University. Humanities \& Social Sciences 10 (2013 6) 1514-1525.

12. Pollay, R.W. and Gallagher, K. (1990), "Advertising and Cultural Values: Reflections in the Distorted Mirror", International Journal of Advertising, Vol. 9 No. 4, pp. 359-372.

13. Polonsky, M. and Carlson, L. (2009), "Is there global inclusion of authors in the five leading advertising journals?", International Journal of Advertising, Vol. 28 No. 4, pp. 691-714.

14. Proctor, S., Proctor, T. and Papasolomou-Doukakis, I. (2002), "A post-modern perspective on advertisements and their analysis", Journal of Marketing Communications, Vol. 8 No. 1, pp. 31-44.

15. Taylor, T. D. (2009), "Advertising and the conquest of culture", Social Semiotics, Vol. 19 No. 4, pp. 405-425. 